\title{
ICE FEATURES OF THE NORTHERN CASPIAN UNDER SEA LEVEL FLUCTUATIONS AND ICE COVERAGE VARIATIONS
}

\author{
Stanislav A. Ogorodov' ${ }^{1}$, Anastasiia A. Magaeva2*, Stepan V. Maznev' ${ }^{1}$ Natalia A. Yaitskaya ${ }^{3}$, \\ Sergey Vernyayev ${ }^{4}$, Anton Sigitov ${ }^{4}$, Yevgeniy Kadranov ${ }^{4}$ \\ 'Lomonosov Moscow State University, Leninskie Gory, 1, 119991, Moscow, Russia \\ ${ }^{2}$ Southern Scientific Centre of Russian Academy of Sciences, Chehova, 41, 344006, Rostov-on-Don, Russia; South \\ Federal University, 105/42, Bolshaya Sadovaya Str., Rostov-on-Don, 344006, Russia \\ ${ }^{3}$ Subtropical Scientific Centre of the Russian Academy of Sciences, 2/28, Yana Fabritsiusa Str., Sochi, 354340, Russia \\ ${ }^{4}$ LLP ICEMAN.KZ; 13, Maily Kozha Str., 060050, Shymkent, Kazakhstan
}

*Corresponding author: a.magaeva@mail.ru

Received: April 20 2020 / Accepted: August $9^{\text {th }}, 2020$ / Published: October 15t, 2020

https://DOI-10.24057/2071-9388-2020-77

\begin{abstract}
The Caspian Sea seasonal ice cover develops each winter despite of it being in mid-latitudes. Increasing development of oil and gas fields challenges researchers to ensure operational safety. The Caspian Sea has seen significant water level fluctuations in its recent history. And in the same time, it is vulnerable to effects of climate change. Extensive studies on ice conditions conducted in the region don't provide insights on influence of these factors in combination to describe ice cover behavior and ice features distribution. We classify winter seasons of the Northern Caspian by their severity calculating the cumulative freezing-degree days (CFDD). Ice charts based on aerial reconnaissance with support of the OSI450 reanalysis provided data on the ice coverage, the timing of ice formation and destruction, the duration of the ice seasons from 1979 to 2015. We analyzed the stamukhi distribution on the Northern Caspian from aerial reconnaissance for 1973-1980 and satellite imagery deciphering for 2013-2019 periods along with sea level dynamics. We found out that the amount of severe and moderate winters reduces while mild winters number increases. This leads to a decrease in the mean ice area and ice duration at the Northern Caspian. Comparison of two periods with different sea levels and ice coverage showed that both factors affect the distribution of stamukhi by depth and distance to coast in the Northern Caspian. Comparison of stamukhi locations in moderate winter seasons showed that their distribution is determined by the area of ice cover. In case of similar ice conditions, the stamukhi distribution is determined by sea level. The zone of their highest concentration shifts along with the coastline offset.
\end{abstract}

KEY WORDS: Northern Caspian, sea level change, ice coverage, stamukhi, ice-gouging area

CITATION: Stanislav A. Ogorodov, Anastasiia A. Magaeva, Stepan V. Maznev, Natalia A. Yaitskaya, Sergey Vernyayev, Anton Sigitov, Yevgeniy Kadranov (2020). Ice Features Of The Northern Caspian Under Sea Level Fluctuations And Ice Coverage Variations. Geography, Environment, Sustainability.

https://DOl-10.24057/2071-9388-2020-77

ACKNOWLEDGEMENTS: The reported study was funded by RFBR. The participation of A. Magaeva is funded according to the research project № 19-35-50086, and the participation of S. Maznev is funded according to the research project

№19-35-90100.

Conflict of interests: The authors reported no potential conflict of interest.

\section{INTRODUCTION}

In recent decades, studies of the ice cover and its effect on seabed have come to the fore in the Russian Arctic (Dubikov et al. 1997; Zubakin 2006; Ogorodov et al. 2013) and Sakhalin (Vershinin et al. 2005). Increasing exploratory and development activities for oil and gas industry is one of the reasons for it. Similar to the Arctic extensive studies on ice cover behaviour were conducted in the Caspian Sea that has seasonal ice cover developing each winter despite of it being in mid-latitudes. This interest is driven with an appraisal of several oil fields both in Russian and Kazakhs sectors of the Northern Caspian and major logistical program to deliver megaunits to Tengiz field onland Eastern coast of the Northern Caspian. Extensive studies were conducted by oil and gas operators (NCOC/Agip KCO, CMOC, Lukoil). Regional monitoring is conducted by state funded agencies both in Kazakhstan and Russian Federation as well as by private ice consulting companies, e.g. Iceman.kz. However, the majority of studies were site-specific for each individual oil field and were rarely conducted for the region in whole. The big picture, however, provides better insight into phenomena and major dependencies with metocean conditions that cause it.

The Caspian Sea is the largest brackish lake in the world, its shallow northern part freezes annually. Due to the unstable hydrometeorological regime in the cold season, the ice conditions of the Northern Caspian Sea, the ice area, thickness and ridge concentration are characterized by significant interannual variability. Maximum ice extent can reach Makhachkala on the west coast and as far as Aktau along the eastern coast. In the Middle Caspian ice appears 
along the coasts only in particularly severe winters, in the southern part, there is no ice at all (Hydrometrology... 1992).

Along with thermal conditions, the main dynamic factors affecting the formation and dynamics of ice cover of the Northern Caspian are winds and short-term and longterm water level fluctuations. These factors determine ice coverage and concentration, its distribution along the water area, ice thickness, and ridge concentration. Cracking and ridging mainly occur at the interface between fast ice and drifting ice. The fast ice boundary position changes through the length of a season, causing active ridging over large areas. Therefore, ice ridges form perpendicular to the wind direction both at the boundary of the stable and in the zones of temporarily stationary ice (Ogorodov et al. 2019). Ice hummocks and ridges grounding in shallow water and further ice pile-up cause the formation of stamukhi (Fig. 1). Movements of ice ridges before grounding to seabed and forming a stamukha lead to mechanical ploughing of seabed, called ice gouging or ice scouring. These processes are associated with the formation of specific landforms (Barnes et al. 1984; Koshechkin 1958). Grounded features sitting heavily on seabed result in formation of pits and exert excess vertical loads. Once breaking up during open water season they can also lead to gouging when they drift off their winter position.

In the Caspian Sea, sea ice and ice features, including ice ridges and stamukhi (massive grounded ice hummocks), were studied since the end of the 19th century by creating 60 ice monitoring points (Hydrometrology... 1992). The Astrakhan meteorological observatory launched ice aerial reconnaissance for the needs of navigation, fishing, and hunting in the winter of 1927-1928. Aerial reconnaissance allowed meteorologists to collect data on the average dates of stamukhi formation, the duration of their persistence and their distribution. The data included the knowledge of typical locations of ice hummocking and ridging zones and ridges concentration. P.I. Bukharitsin (1984) summarized the results of aerial reconnaissance. He identified the stamukhi of autumn and winter origin, as well as single, circular stamukhi and barriers of stamukhi (ridges of stamukhi). P.I. Bukharitsin was the first to show that the number of ice features significantly varies depending on the severity of winters.

B.I. Koshechkin (1958) first considered the effects of ice on the seabed of the Northern Caspian. He found out the traces of the impact of moving ice «pile-ups» («plowing scours») in the area of the Tuleniy Archipelago (the Seal Islands). He showed that an ice hummock with 35-40 cm sail has keel of about $3 \mathrm{~m}$, which exceeds the prevailing depths in that area. The analysis of the distribution of the main scours directions showed a similarity with the directions of the prevailing winds. B.I. Koshechkin proved that the movement of piled ice is subjected to the prevailing winds and currents. On the air reconnaissance data, P.I. Bukharitsin (1984) also estimated the impact of drifting ice on the seabed and coast and considered the influence of the Caspian Sea level on ice ridging processes.

Since the winter of 1978-1979, the satellite data is used to determine the characteristics of the ice cover and to identify ice features'. Since the beginning of the 2000s, the exploration and development of oil deposits on the Caspian shelf caused detailed studies of the stamukhi parameters, grounding process, internal structure (Mironov, Porubaev 2005) and their effect on the seabed (Nepomenko, Popova 2018), modeling (Andreev, Ivanov 2012) and detailed ice monitoring (Frolov et al. 2009). Later Ogorodov and Arkhipov (2010) deteceted the impact of stamukhi and ice ridges on the seabed at depths of up to $12 \mathrm{~m}$ using slide-scan sonar survey.

Stamukha pits (Parr et al. 2013) and ice scours (Fuglem et al. 2013) were studied concerning the assessment of loads on subsea pipelines. Ogorodov et al. (2019) estimated the main depths of the ice effects on the seabed.

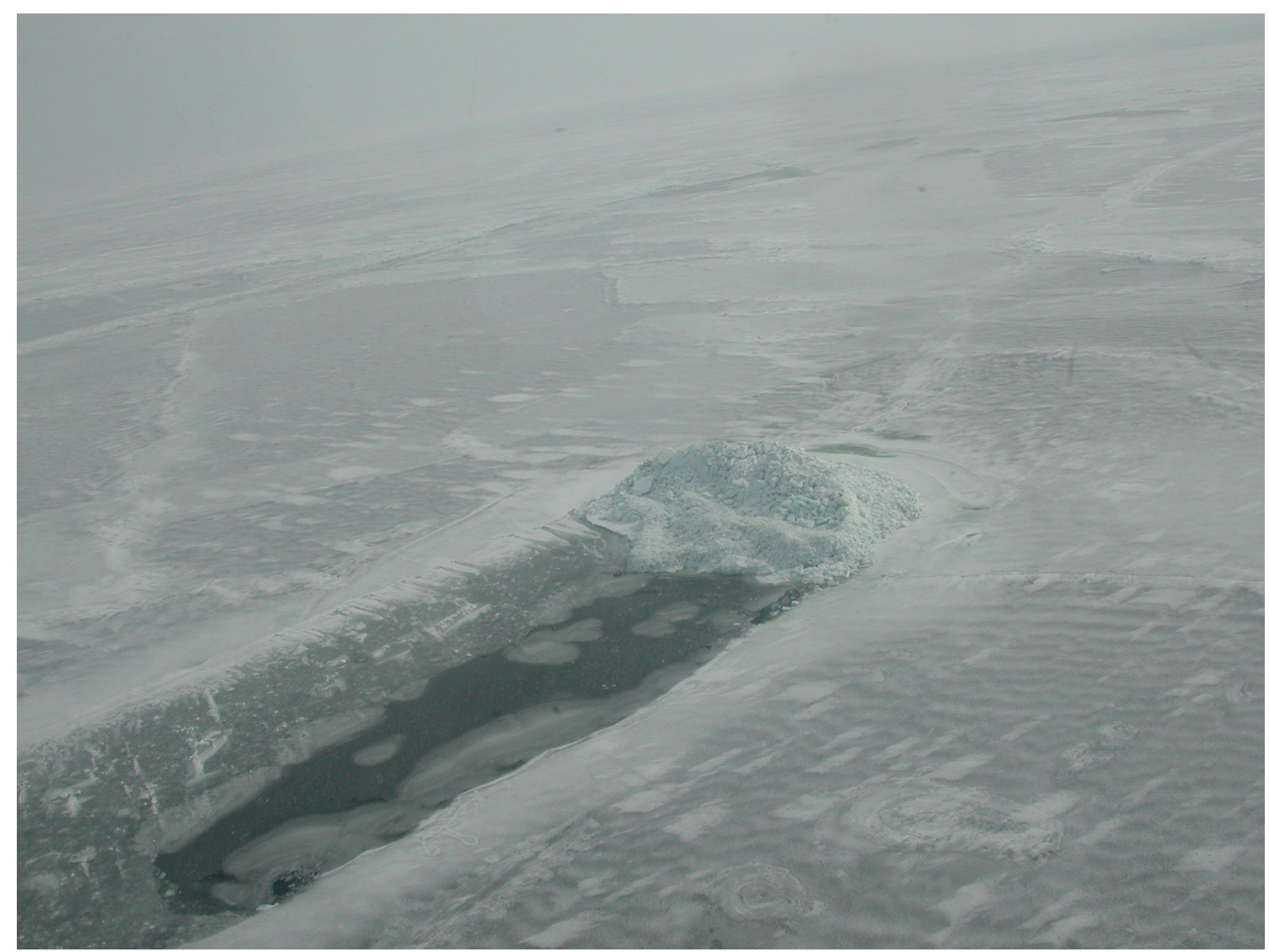

Fig. 1. Stamukha grounded on the Caspian seabed and open water trace behind it 
Comprehensive monitoring of the ice drift (Kadranov et al. 2019), stamukhi distribution, their parameters (Sigitov et al. 2019) and other ice cover characteristics started in 2013 by Ilp iceman.kz. These studies throughout the Northern Caspian are based on continuous monitoring (Fig. 2) and hindcast of both formation and melting of stamukhi as well as provide a whole range of ice information for analysis ${ }^{1}$.

Climate change affects ice conditions and intensity of resulting ice effects to seabed (Ogorodov et al. 2018). In the North Caspian Sea, the position of stamukhi and zones of the most intense ice gouging is changing from year to year depending on the severity of winters. However, their position within one type of winters (mild, moderate or severe), are influenced by the current sea level, bottom topography, wind speed and direction (Bukharitsin et al. 2015).

Water level fluctuation is the main peculiarity of the hydrological regime of the Caspian Sea. Its level is sensitive to changes in the water balance components: the volume of inflowing rivers runoff, evaporation from the water surface and the amount of precipitation within the water area (Klige 1997). The amplitude of the Caspian Sea level fluctuations in the XX - early XXI centuries amounted to a little over 3 meters (Klige 1997).

Water level changes cause significant redistribution of depths, which affect both the sea freeze-up scenarios and the processes of ice ridging (Bukharitsin et al. 2015). Water level fluctuation leads to a bottom topography alteration (Ignatov and Ogorodov 1998) and changes the conditions of the ice features formation and ice gouging (Ogorodov 2011). Thus, the area of mass formation of ridges and stamukhi, as well as the zone of the most intense ice gouging, in similar hydrometeorological conditions is supposed to move along with the current depth change. Ice coverage becomes a decisive factor at certain sea level. This work aims to verify this hypothesis.

\section{MATERIALS AND METHODS}

We classify winter seasons of the Northern Caspian by their severity. This classification reflects the interannual dynamics of winter temperatures, which define the formation of ice in the water area. The most common method of classification of winters by severity is calculating the cumulative freezing-degree days (CFDD). A similar approach for winters typing in the Northern Caspian was used by Tamura-Wicks et al. (2015), Bukharitsin (2008) Fedorenko (2011), Dumanskaya (2013). In this research, we summarized negative air temperatures of winter seasons (from December till March) 1950-2019 from four hydrometeorological stations of the Northern Caspian Astrakhan, Atyrau, Makhachkala, and Fort-Shevchenko. We use open-source data from RIHMI-WDC (Bulygina et al. 2017). The CFDD for four stations were summarized. Then we determine the type of winter season according to the preferred gradations. We classify moderate (normal) winters as winters with CFDD corresponding to the interval from «average minus 20\% amplitude» to «average plus 20\% amplitude». Winters with CFDD in the interval above are classified as mild and in the interval below are indicated as severe. Moreover, two extreme abnormal winters (the coldest and the warmest) are excluded from statistics.

We understand ice coverage as the quotient of observed ice area by the area of the Northern Caspian $\left(90,080 \mathrm{~km}^{2}\right)$, expressed as a percentage. Hereinafter, ice coverage refers to the average ice coverage per season. The ice coverage, freezeup and break-up dates and ice duration of the Northearn Caspian depending on the type of winter were analyzed by standard statistical analysis. The ice charts based on aerial reconnaissance (Hydrometeorological... 1939-1988) and the OSI-450 reanalysis provided data on the ice area. This reanalysis is the second version of SI SAF Global Sea Ice Concentration Climate Data Record (SIC CDR v2.0), which covers the period from 1979 to 2015. That is an open-source data ${ }^{2}$ in NetCDF4 format. It covers the whole globe with a $25 \times 25 \mathrm{~km}$ resolution in Lambert Azimuthal projection 24 hours' time step.

We used the following sources to identify the stamukhi location on the Northern Caspian:

1) Aerial reconnaissance data from 1973 to 1980 collected and processed for the GIS-project «lce regime of Russian southern seas» (Hydrometeorological... 1939-1988; Yaitskaya et al. 2014; Yaitskaya and Magaeva 2018).

2) Stamukhi observation data from satellite imagery analysis (mainly Sentinel-1, usable Sentinel-2, and Landsat, Table 1) from 2013 to 2019 acquired by LLP ICEMAN.KZ.

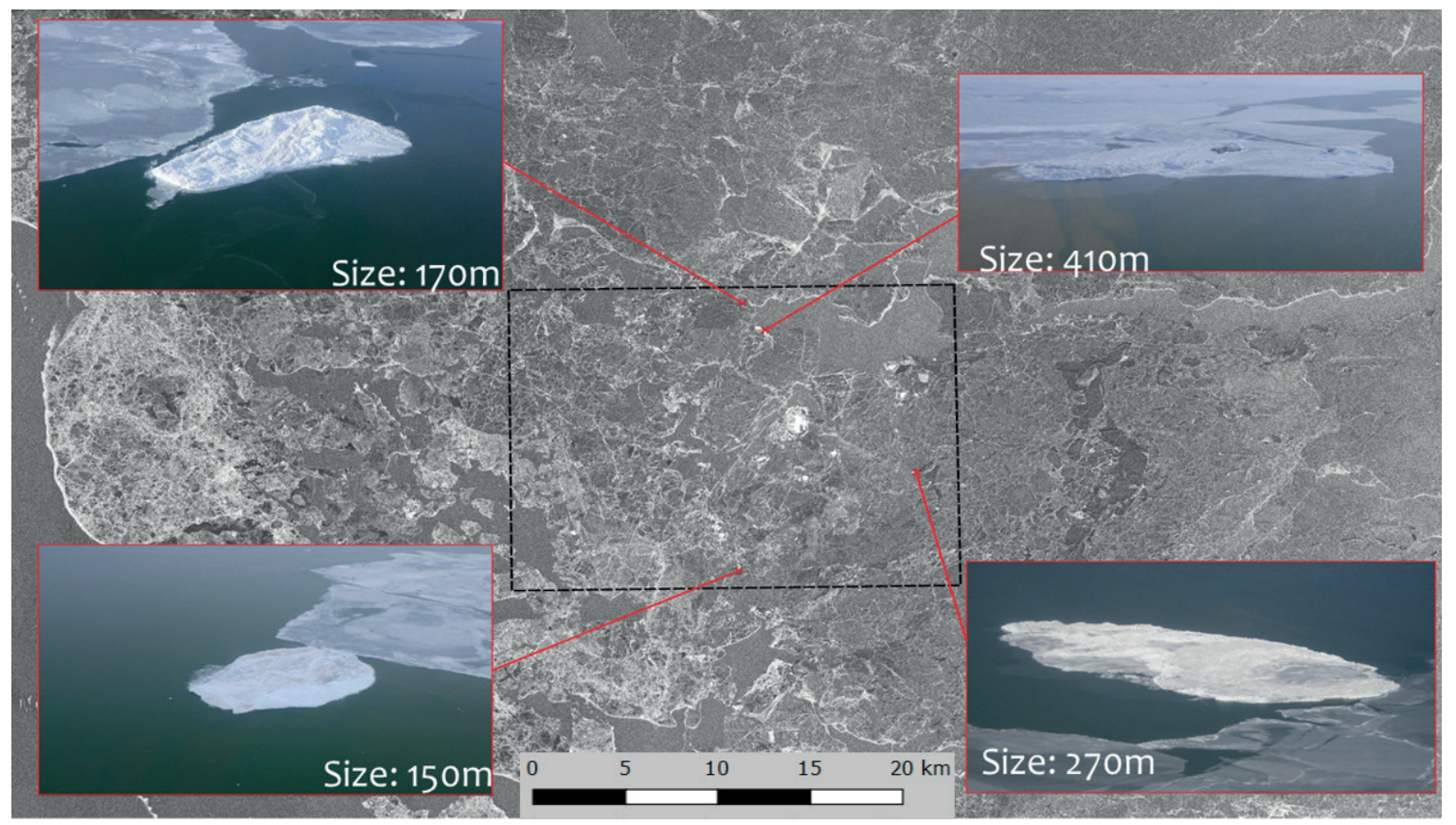

Fig. 2. Aerial photos of stamukhi and their location as detected with Sentinel-1 SAR image (Vernyaeyev et al. 2016)

'https://iceman.kz/

2ftp://osisaf.met.no/ 
The techniques of aerial reconnaissance involve several flights during the winter along regular routes (Guide ... 1953) to the benefit of navigation, fishing, and hunting. As a result, some areas were less studied, and probably not all of the ice features were detected. Aerial reconnaissance was carried out in certain areas with their inherent depths, which affected the distribution of stamukhi by depth and distance from coast. The ice charts were small-scaled, which affected the accuracy of the position assessment of ice features.

The technique of stamukhi deciphering from satellite images, described in detail in (Sigitov et al. 2019), allows observing accurately the entire water area. Hence, in this study, we do not conduct a comparative analysis of the number of stamukhi for 1973-1980 and 2013-2019 seasons. Stamukhi dataset for 2013-2019 is generated using the following algorithm and procedures. During an ongoing season once newly acquired image is available operator performs stamukhi search utilizing internal data management system with the following algorithm. After mobile and stable areas are delineated visual investigation is carried out to spot features containing a point of high response with clear signs of accompanying features indicating presence of an obstacle in moving ice (open water channel left in the drifting ice for example). A lot of targets are found during break-up when opening waters contrast out bright points often with tails of rubble floating downwind.

Width of such features is then measured and accordingly recorded. The record also contains attributes of detection and erosion dates. Detection date is confirmed for each feature by backtracking the stack of season's images to confirm the nearest in time image, when a high response feature is traceable and ice and metocean conditions indicate possibility of stamukhi formation with corresponding ice drift events. In some cases, features found closer to the end of the season are then tracked to the early days of winter, when the first drift events resulted in grounding of ice rubble before the area stabilized for the rest of the season.

Sentinel-2 and Landsat high resolution cloudless and partly cloudy images through the length of the season were thoroughly investigated to confirm the width of each object (maximum dimension) and ensure all the uncertainties with interpretation of SAR images over mainly stationary areas through majority of the season. Once each individual season was processed in such way by one operator and cross-checked by another to reduce bias from human perception all the observations were merged into single database for further analysis and processing.

Processing and analysis of data on the stamukhi distribution were performed in ArcMap 10.3 software. The assessment of the effect of ice features on the seabed is performed using the methodology, described by Ogorodov (2011). The ice conditions data and ice features distribution throughout the water area were aligned with the digital elevation model (DEM) of the bottom topography of the Northern Caspian, created at the Research Laboratory of Geoecology of the North (Moscow State University). We adjusted DEM and coastline for every considered sea level separately. Further, we estimated the intensity of ice impacts on the seabed of the Northern Caspian for 19731980 and 2013-2019 winter seasons, characterized by different sea levels. Mainly we used data on the moderate type of winters since they prevailed and presented in both periods.

We analyzed sea level dynamics in two observation points - Makhachkala and Tyuleniy Island, which have the most complete series of observations. Data obtained from ESIMO open source'. The Caspian Sea level is very unsteady and is characterized by both long-term and short-term fluctuations, caused mainly by wind surges. Thus, we considered the average level values for the winter season (from November to March) in this work.

\section{RESULTS AND DISCUSSION}

The winters of the Northern Caspian were divided into three categories according to their severity: mild, moderate and severe. Moderate types of winters prevail with $59.4 \%$ for the period 1950-2019. The number of severe and mild winters is the same and amounts to 14 of each type (20.3\%). Fig. 3 shows their temporal pattern. From 1950 to 1985 severe winters in the Northern Caspian occurred every 2-5 years, but from 1985 to 2019 only 3 severe winters took place (2002/03, 2007/08, 2011/12).

The most severe winter was in 1953/1954, CFDD amounted minus $1166.5^{\circ} \mathrm{C}$ in Astrakhan. The mildest winter was in 1999/2000, with CFDD minus $78.7^{\circ} \mathrm{C}$. An increase of moderate and mild winters amount undoubtedly affects

Table 1. Utilized satellite mission for stamukhi detection

\begin{tabular}{|c|c|c|c|}
\hline Mission & Instrument & Used bands & Resolution \\
\hline Sentinel-1 & Synthetic Aperture radar (SAR) & C-band, IW mode & $20 \mathrm{~m}$ \\
\hline Sentinel-2 & Multi-spectral instrument (MSI) & $2,3,4$ & $10 \mathrm{~m}$ \\
\hline Landsat-7,8 & Operational Land Imager (OLI) & $2,3,4,8$ (optical) & $15 \mathrm{~m}$ \\
\hline
\end{tabular}

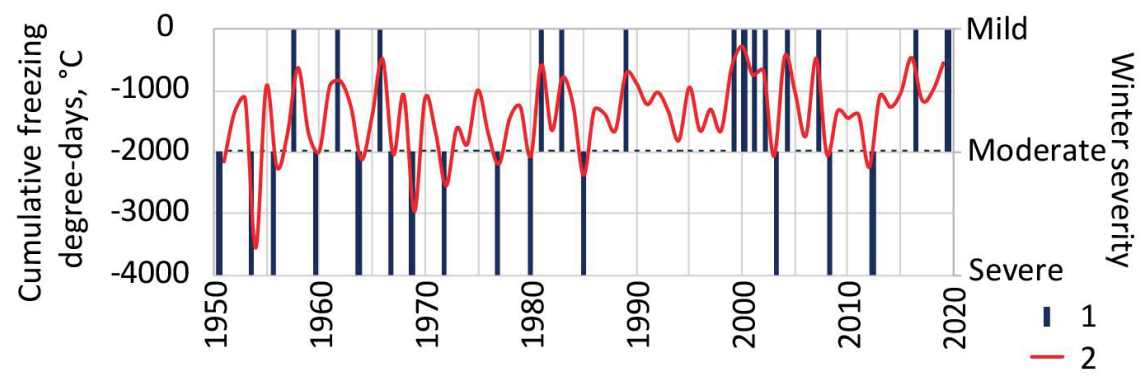

Fig. 3. Winter severity timeline of the Northern Caspian 1-Type of winter (severe, moderate, mild), 2 - cumulative freezing degree-days, ${ }^{\circ} \mathrm{C}$ 
the ice regime. The freeze-up and break-up of sea ice may occur earlier or later depending on severity of winter. In severe winters, first freeze-up happen 1-2 weeks earlier than in moderate and mild winters (Table 2).

Ice coverage of the Northern Caspian varies each season from 30 to 85\% (1999/2000 and 1953/1954 respectively). Long-term average ice coverage is $57 \%$ for the 1940-2019 period.

Figure 4 shows the changes in ice coverage and CFDD for the decades. The decrease of CFDD observed from 1980 causes reduced sea ice coverage. The ice area was analyzed for the 30-year climatic period as recommended by the
World Meteorological Organization (WMO). We considered the CFDD and ice conditions of 1961-1990, 1981-2010 short-term and 1940-2019 long-term periods. The results (Table 3) indicate changes in negative air temperature. Besides, the decrease in ice coverage is 7\%, and ice duration diminished for 5 days in observation point Peshnoy.

Mean Sea level fluctuation is the most important hydrological feature of the Caspian Sea. It spanned around -25.8 $\mathrm{m}$ from the beginning of observations till the XX century. Sea level dropped from the end of the XIX century till 1977 (Fig. 5). The period of 1975-1980 is characterized by the lowest mean sea level (-29.0 m).

Table 2. Long-term freeze-up and break-up average dates of the Northern Caspian

\begin{tabular}{|c|c|c|c|c|c|c|c|c|c|}
\hline \multirow{2}{*}{ Observation point/Winter type } & \multicolumn{3}{|c|}{ Severe } & \multicolumn{3}{c|}{ Moderate } & \multicolumn{3}{c|}{ Mild } \\
\cline { 2 - 11 } & 1 & 2 & 3 & 1 & 2 & 3 & 1 & 2 & 3 \\
\hline Peshnoy peninsula (Atyrau) & 13.11 & 09.04 & 148 & 25.11 & 31.03 & 127 & 26.11 & 12.03 & 107 \\
\hline Tyuleniy Island & 08.12 & 31.03 & 115 & 12.12 & 16.03 & 95 & 21.12 & 22.02 & 64 \\
\hline Astrakhan & 09.12 & 05.04 & 120 & 14.12 & 22.03 & 99 & 26.12 & 06.03 & 71 \\
\hline Kulaly (Tyuleniy Archipelago) & 13.12 & 29.03 & 107 & 15.12 & 14.03 & 127 & 05.01 & 26.02 & 53 \\
\hline
\end{tabular}

1 - freeze-up, 2 - break-up, 3 - ice duration

Table 3. Long-term changes of temperature and ice conditions of the Northern Caspian

\begin{tabular}{|c|c|c|c|}
\hline Parameter / Period & $1940-2019$ & $1961-1990$ & $1981-2010$ \\
\hline Average CFFD 4 observation points, ${ }^{\circ} \mathrm{C}$ & -1378 & -1475 & -1233 \\
\hline Average CFFD Atyrau, ${ }^{\circ} \mathrm{C}$ & -696 & -710 & -597 \\
\hline Mean annual ice coverage, $\%$ & 57 & 57 & 122 \\
\hline Ice duration in Peshnoy, days & $123^{*}$ & 117 \\
\hline
\end{tabular}

*The value was calculated for the period 1940-2015.

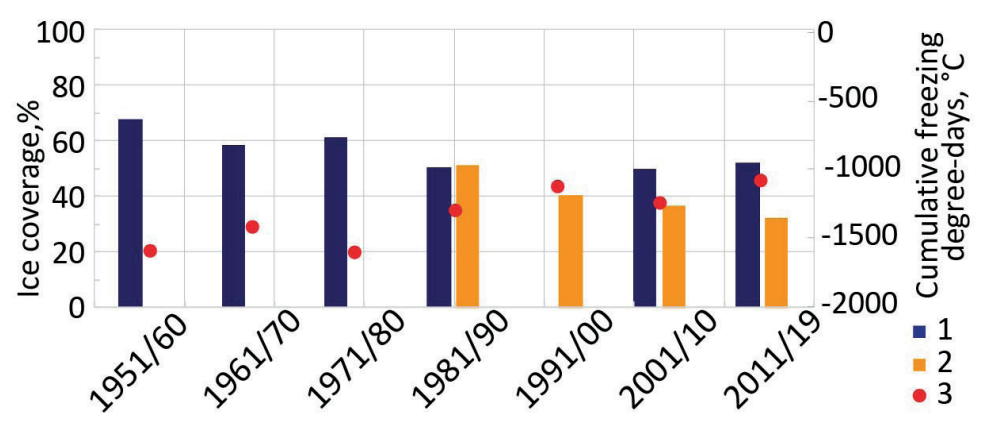

Fig. 4. 10-year averages of sea ice coverage and cumulative freezing degree-days of the Northern Caspian 1-Ice coverage by (Magaeva et al. 2015), 2- Ice coverage by OSI-450, 3 - average cumulative freezing degree-days, ${ }^{\circ} \mathrm{C}$

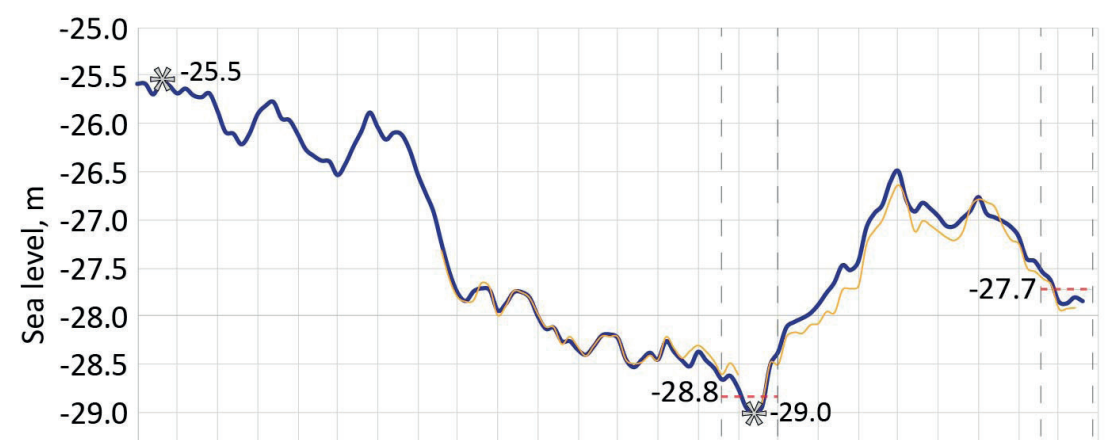

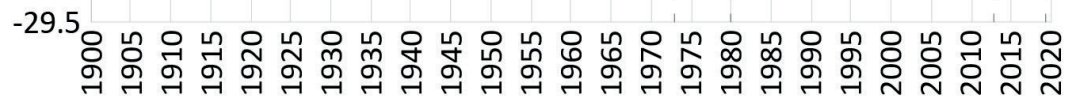
$-1-2--3 \cdots 4$ 解 5 Observation period
}

Fig. 5. Caspian Sea level fluctuations

1 - Observation station Mahachkala, 2 - Observation station Tyuleniy, 3 - periods, 4 - average sea level during periods, 5 - maximum and minimum sea level 
In the XX century, the Caspian Sea level is characterized by periods of rising and dropping. During the period 19001929 sea level was slightly changing, a mean level was -26.2 m. Fast drop by $1.8 \mathrm{~m}$ occurred in 1930-1941. Further sea level slowly decreased from the beginning of the 1940s to 1950s. It stabilized in the 1960s on $-27.4 \mathrm{~m}$ level. But in 1970 the level started to decrease quickly again and reached the lowest position of -29.0 m in 1977 (Matishov et al. 2018). The total mean sea-level drop from 1900 to 1977 was $3.2 \mathrm{~m}$.

From 1978 sea level began to rise dramatically and the mean level reached $-27.2 \mathrm{~m}$. After 1991 sea level was gradually declined and stabilized in 2015 on $-27.9 \mathrm{~m}$. However, in recent years there has been a slight level decline.

In this study, we considered two different periods. $1973-1980$ is characterized by the lowest sea level. The mean level for this period is -28.8 m. In 2013-2019 mean sea level was $-27.7 \mathrm{~m}$.

Sea level affects the location of ice features in the Northern Caspian. The greatest amount of features is observed in moderate winters. We analyzed the water depths of stamukhi (Table 4, Fig. 6). The analysis showed that stamukhi tend to form mostly in the depths of 1.0-6.0 m interval with a peak in 3.0-3.5 m during 1973-1980. The stamukhi were spread down to $11.5 \mathrm{~m}$ depth.

In 2013-2019, the observed depth interval of stamukhi formation remains at 1.0-5.0 $\mathrm{m}$, but peak shifted to the 1.0$1.5 \mathrm{~m}$. The stamukhi were spread down to $10.0 \mathrm{~m}$ depth. In 2013-2019 sea level was higher by $0.9 \mathrm{~m}$ in comparison with 1974-1980. At the same time, ice coverage decreased by $15 \%$.

In contrast with the 1973-1980 period, in 2014-2019 the amount of observed stamukhi increased in the shallow waters of the Volga delta and shoals of the eastern part of the Northern Caspian (from the mouth of the Ural

A

Depth, $m$

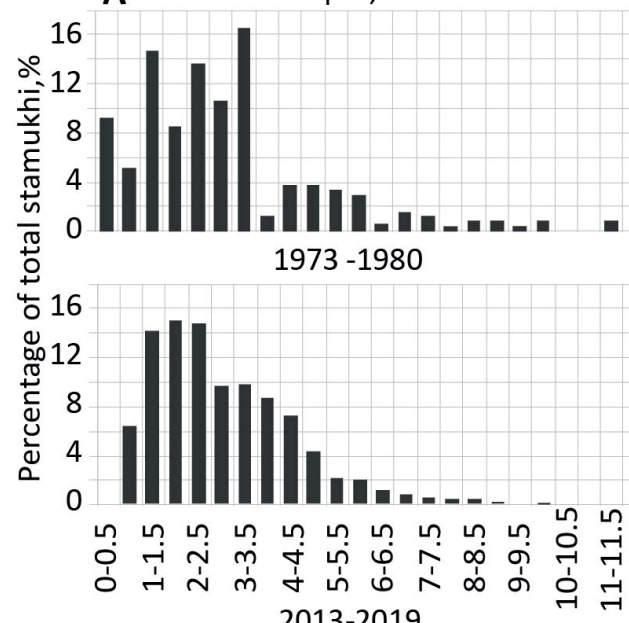

2013-2019
River to the northern coast of the Buzachi Peninsula). Malaya and Srednyaya Zhemchuzhnaya banks became a spot of mass stamukhi grounding. In the western part of the Northern Caspian, stamukhi rarely grounded deeper than $6 \mathrm{~m}$ in 2013-2019, while in 1973-1980 they were distributed down to depths $11 \mathrm{~m}$ or more. We suppose that it is associated with the larger area of ice coverage and lower sea level. At the same time, the low concentration of stamukhi practically does not change in the eastern part of the Northern Caspian, within and around the Ural Furrow with 5-8 $\mathrm{m}$ depths. Due to the mobility of the fast ice boundary position, few large ice hummocks and ridges form, and they can rarely reach the bottom here. Moreover, in the western shallow part, a greater number of stamukhi formed in 2013-2019. Also, a large number of stamukhi that were not previously observed began to form northeast of the Tyuleniy Archipelago. B.I. Koshechkin proved the presence of ice effect on the seabed in this area back in 1958. He showed the presence of small ridges with a calculated draft of $3.0 \mathrm{~m}$, and they very likely to settle in this archipelago with average depths of 1.5-2.0 m. Perhaps the small stamukhi formed here were not observed during aerial reconnaissance.

An analysis of the distance of stamukhi to coast showed that in 2013-2019 they were located closer to coast (Table 4, Fig. 6). In 1973-1980 the highest number of stamukhi was observed in the intervals of 10-15 and 40-55 km with a local minimum in distribution in the interval of 20-40 km. In 2013-2019, the distribution of stamukhi by distance is nearly lognormal with the highest number of stamukhi in 10-30 km from the coast. The number of stamukhi drops at a distance of more than $45 \mathrm{~km}$ from the coast. The average distance and depth over both periods are shown in Table 4.

We suppose that the stamukhi distribution is explained by two main factors: the sea level fluctuations and ice coverage dynamics. We understand sea level as a value

\section{B Distance to coast, $\mathrm{km}$}

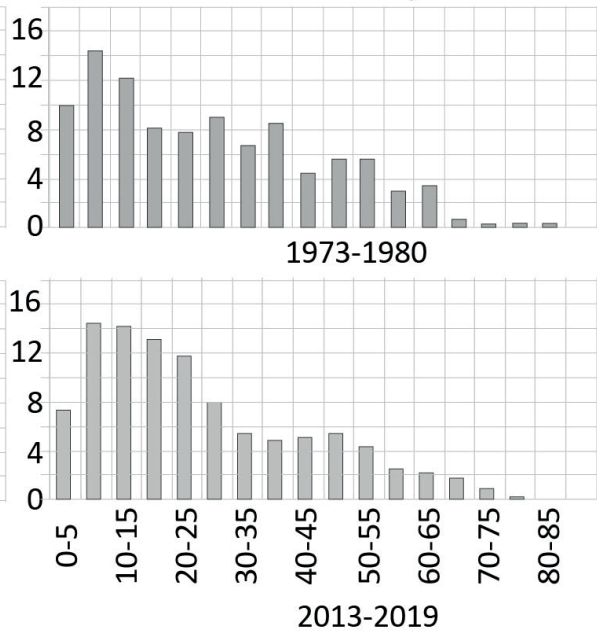

Fig. 6. Stamukhi distribution by water depth (A) and distance to coast (B)

Table 4. Changes of hydrometeorological parameters and stamukhi distribution of the Northern Caspian

\begin{tabular}{|c|c|c|c|}
\hline \multicolumn{2}{|c|}{ Parameter / Period } & $1973-1980$ & 2013-2019 \\
\hline \multicolumn{2}{|c|}{$\Sigma$ CFDD ${ }^{\circ} \mathrm{C}$ (Astrakhan, Atyrau, Machachkala, Tyuleniy) } & -1604 & -907 \\
\hline \multicolumn{2}{|c|}{ Mean annual ice coverage, \% } & 61 & 46 \\
\hline \multirow{2}{*}{ Sea level (winter), m } & Mahachkala & -28.8 & -27.7 \\
\hline & Tyuleniy & -28.7 & -28.0 \\
\hline \multicolumn{2}{|c|}{ Average distance to coast, $\mathrm{km}$} & 27.7 & 24.9 \\
\hline \multicolumn{2}{|c|}{ Average depth of stamukhi locations, m } & 3.0 & 2.3 \\
\hline
\end{tabular}


depending on three parameters: 1) the size of the ice ridge (hummock) keel at the time of grounding, 2) local depth and 3) fluctuations in the general sea level. Until ice hummock penetrates the seabed, it moves with drifting ice. The average ratio of sail and keel sizes is 2.5 (Mironov and Porubaev 2005). The ice ridge size depends on local meteorological conditions (ice thickness, wind strength, ice coverage, etc.), as well as ice strength. The sizes of ice hummocks on the Caspian Sea vary from a few meters to 12 m (Bolgov et al. 2007) and are stochastically distributed. When grounding, both the size of the ice ridge and the local depth matter. Smaller ice ridges run aground at the shallows, larger ones - deeper. Therefore, the depth of stamukha is equally affected by the size of the ice ridge and the local depth, which are practically the same thing. Since the size of ice ridge depends on local shortterm drivers and can vary significantly before grounding, we suppose that in both studied periods the sizes of ice ridges are conditionally the same, both small and large hummocks were presented. After ice ridge stranding ice blocks accumulate on the surface part of the stamukha and significantly change the ratio of sail and keel sizes. It decreases to 0.9 in the Caspian Sea, which is noticeably less than in other seas - 1.3-1.7 (Mironov et al. 2020). Therefore we suppose that fluctuations in the general sea level are decisive in comparison with the size of ice ridge or stamukha.

A change in sea level and ice coverage leads to a change in the ice features locations. To verify this statement, we analyzed the data of winters with different hydrological conditions (Table 5). Such approach helps to compare correctly the data of various quality obtained by different methods.

The winters 1975/1976 and 1977/1978 are characterized by the lowest sea level $-29.0 \mathrm{~m}$, but the ice coverage is different and amounts to $47 \%$ and $58 \%$ respectively. A comparison showed that the increase in the ice area caused changes in stamukhi distribution. They located farther from the coast and deeper. Similar hydrological conditions were observed in the winters of 2014/2015 and $2018 / 2019$. An analysis of the period with relatively stable sea level showed that the area of ice coverage determines the location of the stamukhi, i.e. with an increase in the ice area, stamukhi are grounded deeper. Under similar ice conditions, a level raised by $1 \mathrm{~m}$ becomes a decisive factor. Stamukhi locate closer to the coastline and in shallower waters. It is confirmed by the comparison of the 1977/78 and 2014/2015 seasons. Previously that was suggested by Bukharitsin (Bukharitsin 1994; Bukharitsin et al. 2015).

Sea level fluctuations influence the hydrological regime of the Caspian Sea. It significantly affects the topography of shoals (Ignatov and Ogorodov 1998), can lead to a significant redistribution of depths and restructuring of the bottom topography (Ignatov and Ogorodov 1998). Consequently, sea level fluctuations change the conditions of ice features formation and ice gouging of the seabed and coasts (Ogorodov 2003; 2011). Earlier P.I. Bukharitsin (1984) showed that the sea level decrease in 1974-1980 led to the displacement of the zone most intense ridging to the deeper zone and southward from the coast. In similar conditions of sea level drop at the Aral Sea Maznev et al. (2019) showed the offset of ice features and the most intensive ice gouging area away from the initial coastline. The present study shows that sea level rise by $1 \mathrm{~m}$ leads to changes in stamukhi locations. They locate closer to coast in shallow water (in relation to the $-28 \mathrm{~m}$ sea level) confirming this hypothesis.

Considering the effect of ice features on the seabed it's worth noting that ice hummocks and ridges produce stronger impact than stamukhi. Mobile ridges leave ice scours several kilometres long and up to $5 \mathrm{~m}$ wide (Ogorodov and Arkhipov 2010) during wind drift along with ice floes. Multiple ice scours can reach a width of 200 m. In contrast, stamukhi are immobilized ice features with an effect limited by their size. Nevertheless, large stamukhi produce significant loads on the bottom (Parr et al. 2013) and leave stamukha pits after melting (Ogorodov and Arkhipov 2010). In the case of the sea level rise by $\sim 1 \mathrm{~m}$, stamukhi locate at shallower depths and closer to the coast (in relation to the $-28 \mathrm{~m}$ sea level). This can be dangerous for stable coastal and underwater structures such as pipelines from offshore oil production facilities to refineries onshore. This fact should be considered during the implementation of the Eurasia Canal project (Bekturganov, Bolaev 2017).

We created the integrated chart of the ice-gouging intensity in the Northern Caspian (Fig. 7) considering changes in the ice conditions depending on sea level. First of all, it describes the present conditions but reflects level changes within $\pm 1 \mathrm{~m}$ from current one. According to Ogorodov, 2011 we divide all the ice gouging area of the Northern Caspian into four zones: 1) fast ice zone; 2) zone of fast and drifting ice interaction; 3) drifting ice zone within deep areas; 4) drifting ice area within banks and shoals. In this chart, we consider not only stamukhi distribution but also ice hummocks and ridges, which were detected during the aerial ice reconnaissance of 1973-1980.

Fast ice zone is characterized by limited scour impact of ice features, mainly ice ridges, and grounded hummocks. The intensity of ice gouging is determined by the immobility of fast ice. Bottom scouring by ice floes with frozen ice ridges occurs only during the fast ice break-up. The zone of fast and drifting ice interaction is characterized by intensive scour impact on the seabed by keels of ice ridges on fast ice rim and ice hummocks frozen into drifting ice floes, rarely by stamukhi. Drifting ice zone within deep areas is characterized by intensive scour impact on the seabed by keels of ice ridges frozen into drifting ice floes. Drifting ice zone within banks and shoals is characterized by the most intense scour impact on the seabed by keels of ice ridges frozen into drifting ice floes and large stamukhi.

Table 5. Hydrological parameters and stamukhi distribution of the Northern Caspian

\begin{tabular}{|c|c|c|c|c|c|}
\hline \multicolumn{2}{|c|}{ Parameter / Period } & 1975/1976 & 1977/1978 & $2014 / 2015$ & $2018 / 2019$ \\
\hline \multicolumn{2}{|c|}{ Mean annual ice coverage, $\%$} & 47 & 58 & 57 & 40 \\
\hline \multicolumn{2}{|c|}{ Max ice coverage, $\%$} & 98 & 94 & 75 & 70 \\
\hline \multirow{2}{*}{ Sea level (winter), m } & Mahachkala & -28.99 & -29.00 & -27.80 & -28.00 \\
\hline & Tyuleniy & - & -29.05 & -27.86 & - \\
\hline \multicolumn{2}{|c|}{ Average distance to coast, $\mathrm{km}$} & 18.8 & 30.8 & 29.4 & 21.3 \\
\hline \multicolumn{2}{|c|}{ Average depth of stamukhi locations, m } & 1.9 & 2.9 & 2.8 & 1.9 \\
\hline
\end{tabular}




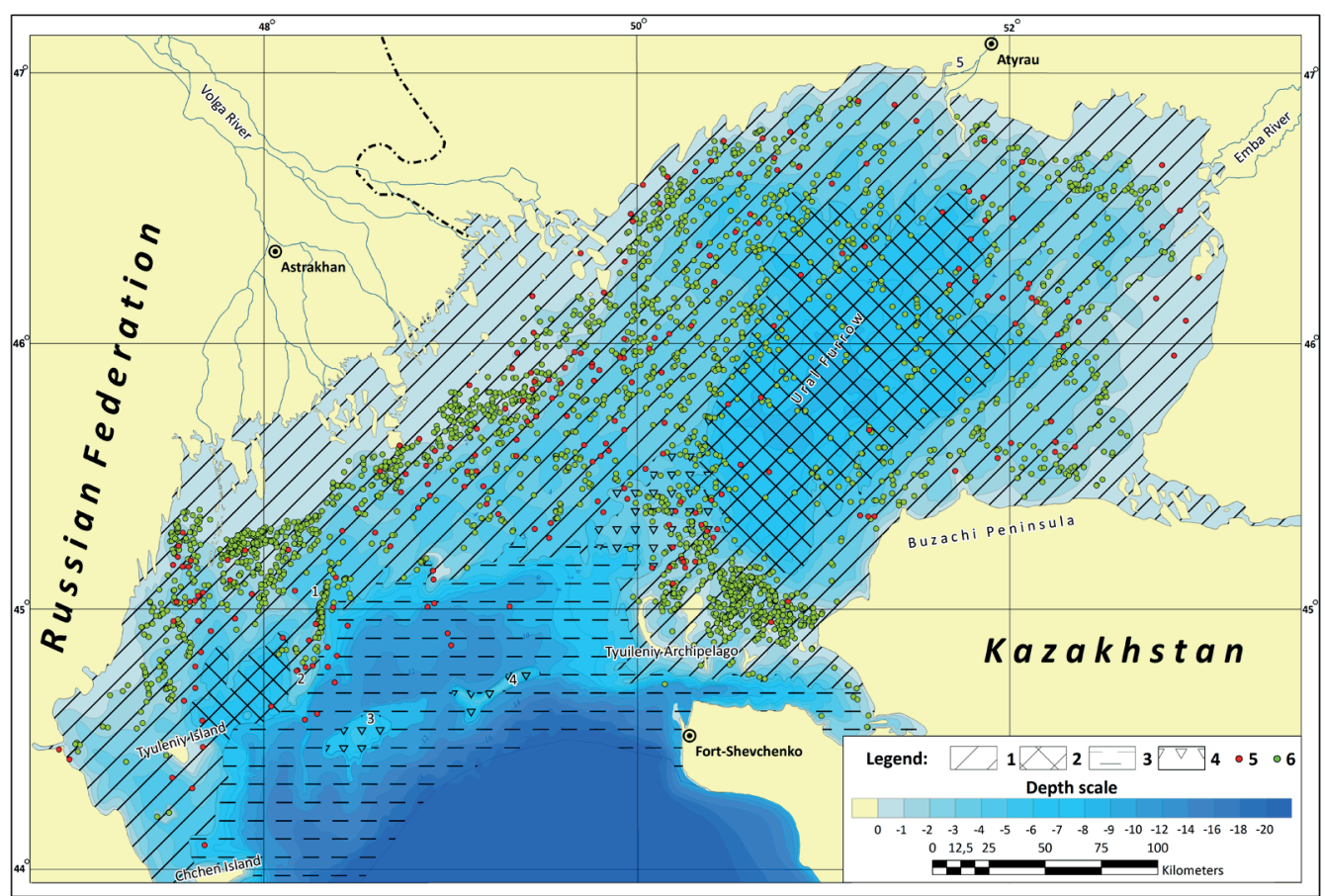

Fig. 7. Chart of ice gouging intensity of the Northern Caspian and stamukhi location

1 - fast ice zone; 2 - fast ice and drifting ice interaction zone; 3 - drifting ice zone in deepwater areas; 4 - drifting ice zone within banks and shoals; stamukhi: 5 - 1973-1980 from aerial reconnaissance (Hydrometeorological... 1939-1988); 6 - 2013-2019 derived from satellite imagery'. Numbers on the map: 1 - Malaya Zhemchuzhnaya bank; 2 - Srednyaya Zhemchuzhnaya bank; 3 - Bolshaya Zhemchuzhnaya bank; 4 - Kulaly bank; 5 - Ural River. Coastline and DEM for -28.0 m mean Caspian Sea level

The ice ridging is a complicated and diversified process. It depends on water depth, embayment of shoreline, and rugged bottom topography, with a large number of banks, spits, and islands (Bolgov et al., 2007). The most complicated is the process of ridging and the formation of stamukhi during the wind-induced water level fluctuations. The highest surge in the Northern Caspian reaches $125 \mathrm{~cm}$ (Nesterov et al. 2018). This value is comparable to longterm fluctuations of sea level over the study period. The unevenness of the coasts determines the spatial differentiation of the surge heights. In all the bays, surges increase to their apex, and vice versa, decrease in convex forms (Ivkina 2013). Storm surges occur both during the formation of the ice coverage and at the period of the stable fast ice. During such surges, ice hummocks and ridges can drift in shallow water, grounding with the level drop, and even remain ashore. Ice floes can overlap and surge over small islands (Bukharitsin 1984). The ice floes create additional resistance to the wind, and fast ice isolates water from the effects of the wind. Thus, ice significantly reduces the height of the surge in comparison with the ice-free period. Depending on the fast ice width and wind characteristics the surge height decreases by $3-5$ times on the average. But thin ice does not prevent the occurrence of surges, but, on the contrary, enhances the impact of ice on the coast (Ivkina 2013). In severe winters, the fast ice extension is holding surges back, suppressing ridging in the coastal zone (Bukharitsin 1984). Surge phenomena pose a significant threat to onshore and coastal infrastructure during the ice season, significantly increasing the intensity of ice effect on the coast.

\section{CONCLUSIONS}

- The analysis of winter air temperature for 1950-2019 indicated that the amount of severe and moderate winters reduces. In the study period recurrence of moderate winters was $60 \%$, severe and mild winters counted $20 \%$ each. Since the 1980s the frequency of mild winters increases. This leads to a decrease in the ice area and the ice duration at the Northern Caspian.

- The analysis of ice coverage of the Northern Caspian for the 30-year climatic periods 1961-1990 and 1981-2010 recommended by the World Meteorological Organization (WMO) showed a 7\% decrease. Moderate winters characterized by the highest ice ridge concentration prevail. That's why the number of ice features did not change significantly.

- Stamukhi distribution depends on local depth including their size and sea level. Assuming the size of the stamukhi to be unchanged, we consider sea level a decisive factor affecting their distribution. Another factor is ice coverage. Comparison of two periods with different sea levels and ice coverage showed that both factors affect the distribution of stamukhi by depth and distance to the coast in the Northern Caspian. A comparison of the stamukhi locations in moderate winter seasons showed that their distribution is determined by the area of ice cover. In case of similar ice conditions, the stamukhi distribution is determined by sea level. The zone of their highest concentration shifts along with the coastline offset. 


\section{REFERENCES}

Andreev O.M., Ivanov B.V. (2012). The use of one-dimensional thermodynamic model for computing the level ice thickness and hummock freezing intensity in the Northern Caspian Sea. Russian Meteorology and Hydrology, 37(1), 34-38, DOI: 10.3103/S1068373912010050.

Barnes P.W., Rearic D.M. and Reimnitz E. (1984). Ice gouging characteristics and processes. The Alaskan Beaufort Sea: Ecosystems and Environments. Orlando: Academic Press, 185-212.

Bekturganov N.S., Bolaev A.V. (2017). The Eurasia Canal as a factor of economic prosperity for the Caspian Region. Geography, Environment, Sustainability, 10(1), 34-43, DOl: 10.24057/2071-9388-2017-10-1-34-43

Bolgov M.V., Krasnozhon G.F. and Lyubushin A.A. (2007). The Caspian Sea: Extreme Hydrological Events Moscow: Nauka. (in Russian). Bukharitsin, P.I. (1984). Ice ridging characteristics in the northern part of the Caspian Sea. Water resources, 6, 115-123. (In Russian). Bukharitsin P.I. (1994). Hazardous hydrological phenomena in the Northern Caspian. Water Resources, 21 (4-5), 444-452. (in Russian). Bukharitsin, P.I. (2008). Comparative characteristics of the long-term ice cover variability the northern part of the Caspian and Azov Seas. Bulletin of Astrakhan state technical university, 3, 207-213 (In Russian). Bukharitsin P.I., Ogorodov S.A. and Arkhipov V.V. (2015). The impact of floes on the seabed of the northern Caspian under the conditions of sea level and ice cover changes. Bulletin of the Moscow State University, Series 5, Geography, 2, 101-108. (in Russian with English summary). Bulygina O.N., Razuvaev V.N., Trofimenko L.T., Shvets N.V. (2017). Description of the dataset of mean monthly air temperature at stations of Russia. [online]. Available at: http://meteo.ru/data/156-temperature\#opisanie-massiva-dannykh [Accessed 10.02.2020].

Dubikov G.I., Sovershaev V.A. and Tuzhilkin V.S. (1997). The natural conditions of the Baydaratskaya Bay. The main research results for the construction of the underwater crossing of the Yamal-Center trunk gas pipeline system. Moscow: GEOC. (in Russian).

Dumanskaya I.O. (2013). Typical conditions on the main shipping lanes of the seas of the European part of Russia for winters of varying severity. Transactions of the Hydrometeorological Research Center of the Russian Federation, 350, 142-166. (In Russian).

Fedorenko A.V. (2011). The study of seasonal and intra-annual variations of the main ice parameters on the southern seas (the Sea of Azov and the Caspian Sea). Proceedings of the SOI, 215, 15-25. (In Russian).

Frolov A.V., Martyshchenko V.A., Asmus V.V., Krovotyntsev V.A., Zemlyanov I.V., Zil'bershtein O.I., Mironov E.A. (2009). Complex studies of hydrometeorological and ice conditions on the northwestern shelf of the Caspian Sea based on satellite and expedition observational data and model calculations. Russian Meteorology and Hydrology, 34(3), 148-158.

Fuglem M., Parr G., Jordaan I., Verlaan P., Peek R. (2013). Sea Ice Scour Depth and Width Parameters for Design of Pipelines in the Caspian Sea. Proceedings of the 22nd International Conference on Port and Ocean Engineering under Arctic Conditions, Espoo, Finland, 9-13 June 2013; Curran Associates, Inc.: Red Hook, NY, USA, 2014.

Guide of production ice air reconnaissance (1953). Leningrad: Hydrometizdat, 185 (in Russian).

Hydrometeorology and Hydrochemistry of the Seas, VI, The Caspian Sea, Issue 1: Hydrometeorological Conditions (1992). St. Petersburg: Gidrometeoizdat. (in Russian). Hydrometeorological Yearbooks (1939-1988). Leningrad: Gidrometeoizdat. (in Russian).

Ignatov E.I. and Ogorodov S.A. (1998). Morphodynamics of the shores of the Caspian Sea under conditions of fluctuations in its level. Regional Research of Russia, 130(6), 27-38. (in Russian).

Ivkina N.I. (2013). Surge phenomena in mouth the zone of the Kazakhstan Sector of Caspian Sea. SOI Proceedings, 214, 278-290 (in

Russian with English summary).

Kadranov Y., Vernyayev S., Sigitov A. (2019). Semi-Automatic Ice Floe Detection for Drift Evaluation. Proceedings of the International

Conference on Port and Ocean Engineering under Arctic Conditions, POAC, 1-14.

Klige R.K. (1997). Variants of forecast of the Caspian Sea level. Geo-ecology of the pre-Caspian zone, 1, 14-27 (in Russian).

Koshechkin B.I. (1958). Traces of the moving ice on the bottom of shallow water areas of the Northern Caspian. Proceedings of Airborne methods laboratory of AS USSR, 6, 227-234. (in Russian).

Magaeva A.A., Yaitskaya N.A., Likhtanskaya N.V., Dashkevish L.V. (2015). Development of geoinformation system of the Russian southern seas ice conditions. Ecology. Economy. Informatics, 269-275. (In Russian with English description).

Matishov D.G., Yaitskaya N.A., Berdnikov S.V. (2018). Temperature and salinity variations in Caspian Sea waters in the 20th century. Oceanology, 58(6), 786-795, DOl: 10.1134/S0001437018060103.

Maznev S.V., Ogorodov S.A., Baranskaya A.V., Vergun A.P., Arkhipov V.V., Bukharitsin P.I. (2019). Ice-gouging topography of the exposed Aral Sea bed. Remote Sensing, 11(2), 1-25, DOl: 10.3390/rs11020113.

Mironov Ye.U., Porubayev V.S. (2005). Structural peculiarities of ice features on the offshore of the Caspian Sea, the Sea of Okhotsk and the Pechora Sea. Proceedings of the 18h International Conference on POAC'05, Potsdam, USA, June 26-30, 2005, 435-434.

Mironov, E.U., Guzenko, R.B., Porubaev, V.S. et al. Morphometry and Internal Structure of Stamukhas in the Ice-covered Seas of Russia.

Russ. Meteorol. Hydrol. 45, 260-268 (2020). https://doi.org/10.3103/S1068373920040068 Nepomenko L., Popova N. (2018). Examination of the Caspian seabed exaration by hummocky icefields with methods of ultrasonic scanning and measurements from ice cover. Astrakhan Bulletin for Environmental Education, 4(46), 35-49. (in Russian with English summary).

Nesterov E.S., Popov S.K. and Lobov A.L. (2018). Statistical Characteristics and Modeling of Storm Surges in the North Caspian Sea. Russian Meteorology and Hydrology, 43 (10), 664-669, DOI: 10.3103/S1068373918100059.

Ogorodov S.A. (2003). The Role of Sea Ice in the Coastal Zone Dynamics of the Arctic Seas. Water Resources, 30(5), 509-518.

Ogorodov S.A. and Arkhipov V.V. (2010). Caspian Sea Bottom Scouring by Hummocky Ice Floes, Doklady Earth Sciences. 432 (1), $703-707$. Ogorodov S.A. (2011). The Role of Sea Ice in Coastal Dynamics. Moscow: Moscow University Press. (in Russian).

Ogorodov S., Arkhipov V., Kokin O., Marchenko A., Overduin P., Forbes D. (2013). Ice effect on coast and seabed in Baydaratskaya Bay, Kara

Sea. Geography, Environment, Sustainability, 3(6), 32-50.

Ogorodov S.A., Arkhipov V.V., Baranskaya A.V., Kokin O.V., Romanov A.O. (2018). The influence of climate change on the intensity of ice gouging of the bottom by hummocky formations. Doklady earth sciences, 478(2), 228-231, DOI: 10.1134/S1028334X1802006X.

Ogorodov S.A., Maznev S.V., Bukharitsin P.I. (2019). Ice gouging topography on the Caspian and Aral Seas bottom. Proceedings of the

Russian Geographical Society, 151(2), 35-50, DOI: 10.31857/S0869-6071151235-50 (in Russian with English summary).

Parr G., Fuglem M., Jordaan I., Verlaan P. (2013). Stamukha Pits - Input Characteristics for Design of Pipelines in the Caspian Sea. Proceedings of the 22nd International Conference on Port and Ocean Engineering under Arctic Conditions, Espoo, Finland, 9-13 June 2013; Curran Associates, Inc.: Red Hook, NY, USA, 2014. 
Sigitov A., Kadranov Y., Vernyayev S. (2019). Analysis of Stamukhi Distribution in the Caspian Sea. Proceedings of the International Conference on Port and Ocean Engineering under Arctic Conditions, POAC, 1-14.

Tamura-Wicks H., Toumi R., Budgell W.P. (2015). Sensitivity of Caspian sea-ice to air temperature. Q. J. R. Meteorol. Soc. 141, 3088-3096, DOI: $10.1002 /$ qj.2592.

Terziev F.S., Kosarev A.N., Kerimov A.A. (1992). Hydrometeorology and Hydrochemistry of Seas, 4: Caspian Sea, 1, Saint Petersburg, Hydrometizdat, 280. (in Russian).

Vernyayev S., Debart C., Kadranov Ye., Sigitov A. (2016). Operational ice charting in midlatitudes using Near Real Time SAR imagery. The Future of Geological Remote Sensing - GRSG, London.

Vershinin S.A., Truskov P.A. and Kuzmichev K.V. (2005). Impact of Ice onto Sakhalin Shelf Constructions. Moscow: Inst. Giprostroymost. (in Russian)

WMO Guidelines for the Calculation of Climatic Norms. Geneva, 2017. WMO, 1203, 32.

Yaitskaya N., Lychagina Yu., Berdnikov S. (2014). The ice conditions study of the Caspian Sea during the winter periods 2008-2010 using satellite monitoring data and geographical information system. Fresenius Environmental Bulletin, 23(11), 2771-2777.

Yaitskaya N.A., Magaeva A.A. Dynamics of the ice regime of the Sea of Azov in the XX-XXI centuries. Led i Sneg. Ice and Snow. 2018, 58(3), 373-386. (in Russian). DOl: 10.15356/2076-6734-2018-3-373-386.

Zubakin G.K. (2006). Ice bodies in the seas of Western Arctic. St. Petersburg: Arctic and Antarctic Research Institute. (in Russian). 